\title{
Methotrexate diethyl ester-loaded lipid-core nanocapsules in aqueous solution increased antineoplastic effects in resistant breast cancer cell line
}

\author{
This article was published in the following Dove Press journal: \\ International Journal of Nanomedicine \\ 25 March 2014 \\ Number of times this article has been viewed
}

\section{Virginia C Yurgel ${ }^{1, *}$ \\ Catiuscia P Oliveira ${ }^{2, *}$ \\ Karine R Begnini' \\ Eduarda Schultze' \\ Helena S Thurow' \\ Priscila MM Leon' \\ Odir A Dellagostin' \\ Vinicius F Campos' \\ Ruy CR Beck ${ }^{2}$ \\ Silvia S Guterres ${ }^{2}$ \\ Tiago Collares' \\ Adriana R Pohlmann ${ }^{2-4}$ \\ Fabiana K Seixas' \\ 'Programa de Pós-Graduação em Biotecnologia (PPGB), Grupo de Pesquisa em Oncologia Celular \\ e Molecular, Laboratório de Genômica Funcional, \\ Biotecnologia/Centro de Desenvolvimento \\ Tecnológico, Universidade Federal de Pelotas, \\ Pelotas, Rio Grande do Sul, Brazil; ${ }^{2}$ Programa de Pós- \\ Graduação em Ciências Farmacêuticas, Faculdade \\ de Farmácia, Universidade Federal do Rio Grande \\ do Sul, Porto Alegre, Rio Grande do Sul, Brazil; \\ ${ }^{3}$ Departamento de Química Orgânica, Instituto de \\ Química, Universidade Federal do Rio Grande do \\ Sul, Porto Alegre, Rio Grande do Sul, Brazil; ${ }^{4}$ Centro \\ de Nanociência e Nanotecnologia, CNANO-UFRGS, \\ Universidade Federal do Rio Grande do Sul, Porto \\ Alegre, Rio Grande do Sul, Brazil}

*These authors contributed equally to this work

Correspondence: Adriana R Pohlmann Departamento de Química Orgânica, Instituto de Química, Universidade

Federal do Rio Grande do Sul, Av Bento

Gonçalves, 9500, PBOX 15003 ,

CEP 9150I-970, Porto Alegre,

Rio Grande do Sul, Brazil

Tel +55 5I 33087237

Email adriana.pohlmann@ufrgs.br

Fabiana K Seixas

Universidade Federal de Pelotas, CDTec/

Biotecnologia, Campus Universitário

Capão do Leão s/n, CEP 960I0-900,

Pelotas, Rio Grande do Sul, Brazil

Tel +55 5332757350

Email seixas.fk@gmail.com
Abstract: Breast cancer is the most frequent cancer affecting women. Methotrexate (MTX) is an antimetabolic drug that remains important in the treatment of breast cancer. Its efficacy is compromised by resistance in cancer cells that occurs through a variety of mechanisms. This study evaluated apoptotic cell death and cell cycle arrest induced by an MTX derivative (MTX diethyl ester $\left.\left[\mathrm{MTX}(\mathrm{OEt})_{2}\right]\right)$ and $\mathrm{MTX}(\mathrm{OEt})_{2}$-loaded lipid-core nanocapsules in two MTX-resistant breast adenocarcinoma cell lines, MCF-7 and MDA-MB-231. The formulations prepared presented adequate granulometric profile. The treatment responses were evaluated through flow cytometry. Relying on the mechanism of resistance, we observed different responses between cell lines. For MCF-7 cells, MTX(OEt) $)_{2}$ solution and MTX(OEt) $)_{2}$-loaded lipid-core nanocapsules presented significantly higher apoptotic rates than untreated cells and cells incubated with unloaded lipid-core nanocapsules. For MDA-MB-231 cells, MTX(OEt) ${ }_{2}^{-}$ loaded lipid-core nanocapsules were significantly more efficient in inducing apoptosis than the solution of the free drug. S-phase cell cycle arrest was induced only by MTX(OEt), solution. The drug nanoencapsulation improved apoptosis induction for the cell line that presents MTX resistance by lack of transport receptors.

Keywords: MTX derivative, resistance, apoptotic cell death, cell cycle arrest, nanocarriers, drug delivery, drug targeting

\section{Introduction}

Breast cancer is the most frequent cancer affecting women. Most of the deaths associated with breast cancer are a result of metastasis and its physiologic effects on morbidity and mortality. ${ }^{1}$ Methotrexate (MTX) is an antimetabolic drug that remains important in the treatment of a variety of malignancies, such as breast cancer. ${ }^{2}$ MTX presents high structural homology to folic acid, being able to bind to folic acid receptor. ${ }^{3}$ The mechanism of action consists of transportation into cells mostly by the reduced folate carrier (RFC). The drug then becomes polyglutamylated to prevent efflux, which effectively traps the molecule inside the cells where it exerts the cytotoxic effect. MTX exerts its toxicity by competitively inhibiting the enzyme dihydrofolate reductase (DHFR). This enzyme is a key factor in DNA synthesis and cell division, due to its involvement in the production of reduced folate needed for the synthesis of thymidylate and purines. ${ }^{2,3}$

Unfortunately, efficacy is often compromised by resistance in cancer cells, which constitutes a major barrier in the effectiveness of anticancer therapy with MTX. ${ }^{4}$ The resistance to MTX occurs through a variety of mechanisms, including reduction of 
MTX uptake by RFC, increase of MTX efflux, a decrease of MTX polyglutamation, and the overexpression of DHFR. ${ }^{4,5}$ Transport of MTX is an essential determinant for generating a sufficient MTX intracellular concentration. ${ }^{6}$

The breast cancer cell lines MCF-7 and MDA-MB231 both demonstrate resistance to MTX, but by distinct mechanisms. MCF-7 cells display an increased $d h f r$ gene copy number, ${ }^{7}$ and overexpression of the $d h f r$ gene is an important mechanism of MTX resistance. The mRNA (messenger ribonucleic acid) upregulation can be explained either by gene amplification of the $d h f r$ locus or by an increase of $d h f r$ transcription rate. The metastatic MDA-MB-231 cells lack expression of $\mathrm{RFC}^{8}$ and therefore are highly resistant to MTX. Heavy promoter methylation is the underlying mechanism for the complete lack of RFC expression in the MDA-MB-231 breast cancer cell line. ${ }^{9}$

Aiming to bypass drug resistance, strategies may consist of chemical modification of MTX ${ }^{10,11}$ and of the design of new drug delivery systems. Nanocarriers have recently emerged as potential drug carriers in cancer therapy due to increased drug efficacy, low toxicity, and ability to minimize multidrug-resistance mechanisms. ${ }^{12}$

Among the different nanocarriers for drug delivery or drug targeting, the lipid nanoparticles and the polymeric nanoparticles represent important systems. ${ }^{13-15}$ Recently, we developed a hybrid system composed of a dispersion of sorbitan monostearate in medium-chain triglycerides, as core, surrounded by a polymeric wall and stabilized by polysorbate 80 micelles. ${ }^{16}$ This hybrid nanocarrier system is called lipid-core nanocapsules (LNCs) due to the vesicular supramolecular structure determined by differential scanning calorimetry, small angle X-ray scattering, ${ }^{17,18}$ and force curve analysis by atomic force microscopy. ${ }^{19}$ An optimal proportion of the raw materials can give formulations by a self-assembly mechanism with high purity. ${ }^{20,21}$ LNCs are interesting nanocarriers for the therapy of tumors as well as inflammatory processes. ${ }^{22-26}$ Acute and subchronic toxicity evaluation carried out in Wistar rats show no appreciable toxicity of these LNCs, indicating that they might be a safe candidate for drug delivery. ${ }^{27}$

Considering that in vitro cell culture systems provide a rapid and effective means to assess parameters and responses, our objective was to evaluate apoptotic cell death and cell cycle arrest induced by an MTX derivative (MTX diethyl ester [MTX $\left.(\mathrm{OEt})_{2}\right]$ ) and MTX(OEt) -loaded LNCs in two breast adenocarcinoma cell lines, MCF-7 and MDA-MB-231.

\section{Materials and methods Materials}

Poly( $\varepsilon$-caprolactone) (molecular weight $=14,000 \mathrm{~g} \mathrm{~mol}^{-1}$ ), Span $60^{\circledR}$ (sorbitan monostearate), N,N-dicyclohexylcarbodiimide (DCC), 4-(N,N-dimethyl)aminopyridine (DMAP) were obtained from Sigma-Aldrich (St Louis, MO, USA). Polysorbate 80 and caprylic/capric triglyceride were supplied by Delaware (Porto Alegre, Brazil). MTX was supplied by Pharma Nostra (Annapolis, Brazil). All other chemicals and solvents used were of analytical or pharmaceutical grade. All reagents were used as received.

\section{Methods}

\section{Preparation of MTX $(\mathrm{OEt})_{2}$-loaded LNCs}

Initially, the $\operatorname{MTX}(\mathrm{OEt})_{2}$ was prepared as previously reported, ${ }^{28}$ using DMAP (6 mg, $0.4 \mathrm{mmol}$ ) as catalyst and DCC (416 mg, $2 \mathrm{mmol}$ ) as coupling agent. The chemical identity of diethyl (2S)-2-[(4-\{[(2,4-diaminopteridin-6-yl) methyl](methyl)amino benzoyl)-amino]-pentanedioate was confirmed by proton nuclear magnetic resonance ( ${ }^{1} \mathrm{H}$ NMR) spectroscopy (INOVA-300; Varian Medical Systems, Inc., Palo Alto, CA, USA). ${ }^{1} \mathrm{H}$ NMR $300 \mathrm{MHz}(\delta$, ppm) dimethyl sulfoxide (DMSO)- $d_{6}: 8.58$ (s, $1 \mathrm{H}, \mathrm{H}-6$ pteridinyl), 8.33 (d, $1 \mathrm{H} J=8.3 \mathrm{~Hz}, \mathrm{NHCO}$ ), 7.75 and 6.82 (two d, 4H, $J=9 \mathrm{~Hz}, \mathrm{C}_{6} \mathrm{H}_{4}$ ), 7.5 (br s, 2H, $\mathrm{NH}_{2}$ ), 6.68 (br s, $2 \mathrm{H}, \mathrm{NH}_{2}$ ), $4.77\left(\mathrm{~s}, 2 \mathrm{H}, \mathrm{CH}_{2} \mathrm{~N}\right), 4.40\left(\mathrm{~m}, 1 \mathrm{H}, \mathrm{NHC}^{\mathrm{HCO}} \mathrm{E}_{2} \mathrm{Et}\right), 4.07$ (m, $\left.4 \mathrm{H}, 2 \times \mathrm{OCH}_{2} \mathrm{CH}_{3}\right), 3.21\left(\mathrm{~s}, 3 \mathrm{H}, \mathrm{CH}_{3} \mathrm{~N}\right), 2.40(\mathrm{~m}, 2 \mathrm{H}, J=7.2$ $\left.\mathrm{Hz}, \mathrm{CH}_{2} \mathrm{CO}_{2} \mathrm{Et}\right), 2.05\left(\mathrm{~m}, 2 \mathrm{H}, \mathrm{CHCH}_{2} \mathrm{CH}_{2}\right), 1.17$ (m, 6H, $2 \times \mathrm{OCH}_{2} \underline{\mathrm{CH}}_{3}$ ).

LNCs were prepared using the methodology of selfassembling as previously described. ${ }^{20,21} \mathrm{Poly}$ ( $\varepsilon$-caprolactone) $(0.100 \mathrm{~g})$, sorbitan monostearate $(0.038 \mathrm{~g})$, capric/caprylic triglyceride $(160 \mu \mathrm{L})$ and $\operatorname{MTX}(\mathrm{OEt})_{2}(0.005 \mathrm{~g})$ were dissolved in acetone $(27 \mathrm{~mL})$ at $40^{\circ} \mathrm{C}$. A turbid solution was instantaneously obtained by injecting this organic phase into an aqueous phase containing polysorbate $80(0.077 \mathrm{~g})$ dissolved in water $(53 \mathrm{~mL})$ at $40^{\circ} \mathrm{C}$. After 10 minutes, the acetone was evaporated, and the suspension concentrated under reduced pressure at $40^{\circ} \mathrm{C}$. The final volume was adjusted to $10 \mathrm{~mL}$ in a volumetric flask. This formulation was named MTX $(\mathrm{OEt})_{2}$-LNC.

A blank formulation of LNCs was also prepared as control as described above but omitting the $\operatorname{MTX}(\mathrm{OEt})_{2}$.

\section{Particle size and size distribution of LNCs}

The granulometric profiles were determined using three different techniques: laser diffraction (range from $40 \mathrm{~nm}$ to $2 \mathrm{~mm}$ ), photon correlation spectroscopy (PCS) (range from 
0.6 to $5,000 \mathrm{~nm}$ ), and nanoparticle tracking analysis (NTA) $(10-1,000 \mathrm{~nm})$. Laser diffraction (Malvern Mastersizer ${ }^{\circledR}$ 2000; Malvern Instruments, Malvern, UK) was used to obtain the median diameter based on the number of particles $\left(D_{[n, 0.5]}\right)$ and volume-weighted mean diameters $\left(D_{4,3}\right)$. The polydispersity of particle sizes was calculated as span, which is the width of the distribution based on $10 \%, 50 \%$, and $90 \%$ of the cumulative size distribution. The experimental procedure consisted of adding the liquid turbid solution of nanocapsules in the wet unit of the instrument containing distilled water. The analysis was carried out at room temperature in triplicate $(n=3)$ batches for each formulation (LNC and MTX(OEt) $\left.)_{2}-\mathrm{LNC}\right)$. The volume of each formulation was that for an adequate obscuration $(2.0 \%-8.0 \%)$.

PCS was carried out using a Zetasizer Nano ZS (Malvern Instruments) considering the specificity of this technique to characterize the nanometric population of colloidal solutions. To avoid sample selection, only the diluent was filtered before the sample preparation. The LNC and MTX(OEt) LNC batches were not treated before dilution. The average diameters ( $Z$-average calculated by the cumulants) were determined after diluting the formulation aliquots $(500 \times)$ in ultrapure water, at $25^{\circ} \mathrm{C}$. All samples were analyzed in triplicate batches.

NTA was carried out in a NanoSight (LM10; NanoSight Ltd., Salisbury, UK) instrument using NTA 2.0 (NanoSight Ltd.) analytical software. Brownian motion of the individual particles was followed in real-time via CCD (charge-coupled device) camera. The particles were analyzed after dilution with water by a laser diode ( $635 \mathrm{~nm}$ wavelength). The formulations were diluted 5000× using ultrapure water (Milli-Q ${ }^{\circledR}$; Merck KGaA, Darmstadt, Germany), and each video clip was captured over 60 seconds. The automatic detection threshold was enabled, and the maximum particle jump was set at 10 in the NTA software. All measurements were performed in triplicate batches.

\section{$\mathrm{pH}$ measurements and zeta potential}

The $\mathrm{pH}$ values of the suspensions were measured without prior dilution using a calibrated potentiometer B474 (Micronal, SA, Sao Paulo, Brazil) at $25^{\circ} \mathrm{C}$.

The zeta potential was analyzed in Zetasizer Nano ZS. The analysis is based on laser Doppler velocimetry and deduced from the electrophoretic mobility $\left(\mathrm{U}_{\mathrm{E}}\right)$. The samples were diluted (500×) in $10 \mathrm{~mm} \mathrm{NaCl}$ aqueous solution, and to avoid any sample selection, the formulations were added into pre-filtered medium without treatment (centrifugation or filtration). All samples were analyzed in triplicate batches at $25^{\circ} \mathrm{C}$.

\section{Quantification of MTX $(\mathrm{OEt})_{2}$ in the LNC} formulation

$\operatorname{MTX}(\mathrm{OEt})_{2}$ was quantified by high performance liquid chromatography (HPLC). The HPLC system consisted of a PerkinElmer S-200 (PerkinElmer, Waltham, MA, USA) with an S-200 injector, an ultraviolet-visible detector, a guardcolumn, and a column (Spherisorb ${ }^{\circledR}$ ODS2, $150 \mathrm{~mm} \times 4 \mathrm{~mm}$, $4 \mu \mathrm{m}$; Waters Corporation, Milford, MA, USA). MTX $(\mathrm{OEt})_{2}$ was detected at $303 \mathrm{~nm}$ using a mobile phase $\left(1.0 \mathrm{~mL} \mathrm{~min}^{-1}\right)$ of methanol/water $(80: 20 \mathrm{v} / \mathrm{v})$ adjusted to an apparent $\mathrm{pH}$ of $4.0 \pm 0.5$ with $10 \%(\mathrm{v} / \mathrm{v})$ acetic acid. The method was previously validated ${ }^{28}$ considering the linearity ( $\left.r=0.998\right)$, precision, and repeatability (relative standard deviation $<4 \%$ ), accuracy $(100 \% \pm 1 \%)$, limit of quantification $(1 \mu \mathrm{g} \mathrm{mL}-1)$ and recovery data $(101 \pm 1)$.

The total drug content was determined by HPLC after dissolving an aliquot of the formulation in acetonitrile using a volumetric flask $(10 \mathrm{~mL})$. The solution was filtered $(0.45 \mu \mathrm{m}$; Merck KGaA) and injected $(20 \mu \mathrm{L})$. This experiment was carried out in triplicate batches $(n=3)$. The $\mathrm{MTX}(\mathrm{OEt})_{2}$, retention time was 22.4 minutes under the conditions of the analysis.

The encapsulation efficiency was determined by ultrafiltration-centrifugation using a Microcon ${ }^{\circledR}$ centrifugal filter device (10 kDa; Merck KGaA). An aliquot of the formulation was directly placed in the filter device for centrifugation at $1844 \times g$ for 5 minutes (Sigma ${ }^{\circledR} 1$-14; SIGMA Laborzentrifugen $\mathrm{GmbH}$, Osterode am Harz, Germany). The ultrafiltrate was analyzed by HPLC without dilution. The encapsulation efficiency was calculated by dividing the difference between the total drug content and the drug concentration in the ultrafiltrate by the total drug content, and multiplied by 100 .

\section{Cell culture studies}

Human breast adenocarcinoma MCF-7 and MDA-MB231 cell lines were obtained from the Rio de Janeiro Cell Bank (PABCAM, Federal University of Rio de Janeiro, Rio de Janeiro, Brazil) and routinely cultured in our laboratory. MCF-7 cells were cultured in RPMI (Roswell Park Memorial Institute) 1640 medium (purchased from Vitrocell Embriolife, Campinas, Brazil) supplemented with $20 \%$ fetal bovine serum (FBS), 1\% L-glutamine, and 1\% penicillin/streptomycin. MDA-MB-231 cells were cultured in LEIBOVITZ L-15 medium (purchased from Cultilab, Campinas, Sao Paulo, Brazil) supplemented with 10\% FBS, $1 \%$ L-glutamine, $1 \%$ penicillin, and $0.2 \mathrm{mg} / \mathrm{mL}$ sodium bicarbonate. FBS was purchased from Gibco (Life Technologies, Carlsbad, CA, USA). Cells were grown at $37^{\circ} \mathrm{C}$ in an atmosphere of $95 \%$ humidified air and $5 \% \mathrm{CO}_{2}$. The 
experiments were performed with cells in the logarithmic phase of growth. Apoptosis experiments were performed in triplicate, and cell cycle experiments were performed in duplicate. The treatments tested consisted of $\mathrm{MTX}(\mathrm{OEt})_{2}$ and $\operatorname{MTX}(\mathrm{OEt})_{2}$-LNC formulations at 20, 10, and $5 \mu \mathrm{M}$ concentrations and also LNC at the equivalent amounts used for the drug nanoformulation. Cells without any treatment were used as controls in all experiments. A control consisting of LNC plus the solution of the free drug was also evaluated.

\section{Flow cytometric analysis of apoptosis}

Cells were seeded in 6-well plates at a density of $2 \times 10^{5}$ per well and grown for 24 hours at $37^{\circ} \mathrm{C}$ in a humidified atmosphere of $5 \% \mathrm{CO}_{2}, 95 \%$ air. The cells were then incubated for 48 hours with $\mathrm{MTX}(\mathrm{OEt})_{2}$, solution and MTX $(\mathrm{OEt})_{2}$-LNC at concentrations of 20,10 , and $5 \mu \mathrm{M}$, and also with LNC and LNC plus $\operatorname{MTX}(\mathrm{OEt})_{2}$, solution at the equivalent amounts. Apoptotic cell death was evaluated by flow cytometry using Guava Nexin ${ }^{\circledR}$ (Merck KGaA) reagent kit and analyzed in a Guava ${ }^{\circledR}$ Flow Cytometry easyCyte ${ }^{\mathrm{TM}}$ System (Merck KGaA) plus flow cytometer. After the 48-hour treatment, culture medium was removed and placed in a centrifuge tube. Cells were washed with phosphate-buffered saline, which was also placed in the centrifuge tube. Cells were then harvested by trypsinization, transferred to the tube and centrifugated at $300 \times g$ for 7 minutes. The medium was aspirated carefully, to not disturb the pellet, and cells were resuspended in fresh serum-containing medium. Cells were counted to adjust cell concentration and then stained following manufacturer's instructions.

Early apoptotic cells can be identified by annexin V-phycoerythrin (PE; Merck KGaA) binding because of a high affinity toward phosphatidylserine residues which are externalized from inner to outer surfaces of cell membranes during early stages of apoptosis. On the other hand, the cell impermeant dye 7-AAD (7-aminoactinomycin D; Merck $\mathrm{KGaA}$ ) identifies late apoptotic and necrotic cells having damaged plasma membrane. ${ }^{29}$

\section{Flow cytometric analysis of late apoptosis} Cells were treated with MTX $(\mathrm{OEt})_{2}$ solution and $\mathrm{MTX}(\mathrm{OEt})_{2}{ }^{-}$ LNC at concentrations of 20,10 , and $5 \mu \mathrm{M}$, and also with LNC and LNC plus MTX $(\mathrm{OEt})_{2}$ solution at the equivalent amounts for 48 hours and the Guava ${ }^{\circledR}$ TUNEL assay (Merck $\mathrm{KGaA}$ ) was conducted following the manufacturer's instructions. Briefly, treated cells were subjected to cell fixation procedure with $50 \mu \mathrm{L}$ of $4 \%(\mathrm{w} / \mathrm{v})$ paraformaldehyde in phosphate-buffered saline for 60 minutes at $4^{\circ} \mathrm{C}$ and then with $200 \mu \mathrm{L}$ of ice-cold $70 \%(\mathrm{v} / \mathrm{v})$ ethanol at $-20^{\circ} \mathrm{C}$ for at least
18 hours. For the staining procedure, $1.5 \times 10^{4}$ to $1.0 \times 10^{5}$ of fixed cells were washed twice followed by addition of $25 \mu \mathrm{L}$ of DNA Labeling Mix (Roche, Basel, Switzerland) for 60 minutes at $37^{\circ} \mathrm{C}$. At the end of the incubation time, cells were centrifugated and resuspended in $50 \mu \mathrm{L}$ of the AntiBrdU Staining Mix (Merck KGaA). Cells were incubated in the dark at room temperature for 30 minutes, and samples were acquired on flow cytometry (Guava ${ }^{\circledR}$ Flow Cytometry easyCyte $^{\mathrm{TM}}$ System). In this assay, terminal deoxynucleotidyl transferase (TdT) catalyzes the incorporation of BrdU (5-bromo-2'-deoxyuridine) residues into the fragmenting nuclear DNA of apoptotic cells at the $3^{\prime}$-hydroxyl ends by nicked-end labeling. Tetramethylrhodamine-conjugated anti-BrdU antibody binds to the incorporated BrdU residues, labeling the mid- to late-stage apoptotic cells.

\section{Cell cycle analysis}

Cell populations at the different phases of cell cycle (G0/G1, $\mathrm{S}$, and $\mathrm{G} 2 / \mathrm{M}$ ) were analyzed by flow cytometry after cells were maintained for 48 hours in the presence of $\mathrm{MTX}(\mathrm{OEt})_{2}$ solution and $\operatorname{MTX}(\mathrm{OEt})_{2}-\mathrm{LNC}$ at concentrations of 20 and $5 \mu \mathrm{M}$, and also of LNC at the equivalent amounts. Before treatment, cells were synchronized by removal of FBS supplementation of culture medium. Cell cycle evaluation was performed by propidium iodide staining using Guava ${ }^{\circledR}$ Cell Cycle (Merck KGaA) reagent kit, and analyzed in a Guava ${ }^{\circledR}$ Flow Cytometry easyCyte ${ }^{\mathrm{TM}}$ System plus flow cytometer. After 48 hours treatment, cells were detached, fixed, and stained according to the manufacturer's protocol.

\section{Data analysis}

Datasets were analyzed using one-way analysis of variance followed by a Tukey test for multiple comparisons. Significance was considered at $P<0.05$ in all analyses. Data were expressed as mean \pm standard error of the mean.

\section{Results}

\section{MTX(OEt) ${ }_{2}$-loaded LNCs: particle size distribution, polydispersity, $\mathrm{pH}$, and zeta potential}

The MTX $(\mathrm{OEt})_{2}$ derivative was obtained in $70 \%$ of yield. The NMR spectrum showed the characteristic signals attesting its chemical identity. The MTX $(\mathrm{OEt})_{2}$-LNC formulation showed macroscopically a homogeneous milky appearance after preparation.

The formulations presented zeta potential of $-9 \pm 4 \mathrm{mV}$ and $-8 \pm 5 \mathrm{mV}$, and $\mathrm{pH}$ of $6.10 \pm 0.17$ and $5.85 \pm 0.56$ for $\mathrm{LNC}$ and $\operatorname{MTX}(\mathrm{OEt})_{2}-\mathrm{LNC}$, respectively (Table 1$)$. 
Table I Characterization of formulations by LD, PCS, NTA, zeta potential, and $\mathrm{pH}$

\begin{tabular}{llll}
\hline Technique & Parameter & LNC & $\begin{array}{l}\text { MTX(OEt) })_{2}^{-} \\
\text {LNC }\end{array}$ \\
\hline LD & $\mathrm{D}_{4,3}(\mathrm{~nm})$ & $215 \pm 6$ & $181 \pm 42$ \\
& $\mathrm{D}_{[\mathrm{n}, 0.5]}(\mathrm{nm})$ & $66 \pm 0$ & $66 \pm \mathrm{I}$ \\
& Span & $1.8 \pm 0.1$ & $1.6 \pm 0.1$ \\
PCS & z-average $(\mathrm{nm})$ & $208 \pm 54$ & $183 \pm 7$ \\
& PDI & $0.09 \pm 0.02$ & $0.06 \pm 0.02$ \\
& Zeta potential $(\mathrm{mV})$ & $-9 \pm 4$ & $-8 \pm 5$ \\
NTA & Mean size $(\mathrm{nm})$ & $221 \pm 11$ & $197 \pm 13$ \\
& $\mathrm{D}_{[\mathrm{n}, 0.5]}(\mathrm{nm})$ & $212 \pm 20$ & $177 \pm 27$ \\
& Particle number & $5.5 \times 10^{12} \pm$ & $5.5 \times 10^{12} \pm$ \\
& $\left(\right.$ particles mL $\left.{ }^{-1}\right)$ & $0.5 \times 10^{12}$ & $0.1 \times 10^{12}$ \\
& $\mathrm{PH}$ & $6.10 \pm 0.17$ & $5.85 \pm 0.56$ \\
\hline
\end{tabular}

Note: Data are expressed as mean \pm standard deviation.

Abbreviations: $D_{4,3}$, volume-weighted mean diameters; $D_{[n, 0.5]}$, median diameters based on the number of particles; LD, laser diffraction; MTX(OEt) $)_{2}-\mathrm{LNC}$ methotrexate diethyl ester-loaded nanocapsule; NTA, nanoparticle tracking analysis: $\mathrm{PCS}$, photon correlation spectroscopy; PDI, polydispersity index.

The granulometric profiles based on volume, determined by laser diffraction, showed values for $\mathrm{D}_{[\mathrm{n}, 0.5]}$ of $66 \pm 0 \mathrm{~nm}$ and $66 \pm 1 \mathrm{~nm}$ and for volume-weighted mean diameters $\left(\mathrm{D}_{4,3}\right)$ of $215 \pm 6 \mathrm{~nm}$ and $181 \pm 42 \mathrm{~nm}$ for the $\mathrm{LNC}$ and MTX(OEt) $)_{2}-\mathrm{LNC}$, respectively. All formulations had median diameters, based on the number $\left(\mathrm{D}_{[\mathrm{n}, 0.5]}\right)$ of particles, lower than $100 \mathrm{~nm}$ (Table 1). For the unimodal distributions, span values of $1.8 \pm 0.1$ (LNC) and 1.6 \pm 0.1 (MTX(OEt) $\left.{ }_{2}-\mathrm{MNC}\right)$ indicated narrow particle size distributions for both formulations (Table 1).

PCS and NTA were used to detail the nanoscopic populations of LNC and MTX $(\mathrm{OEt})_{2}$-LNC. Considering the PCS analysis, particle size profiles were unimodal (Figure 1) with z-average diameters varying from $208 \pm 54 \mathrm{~nm}$ to $183 \pm 7 \mathrm{~nm}$ with narrow size distributions (polydispersity index $<0.10$ ) to LNC and $\mathrm{MTX}(\mathrm{OEt})_{2}-\mathrm{LNC}$, respectively. NTA analysis showed, for $\mathrm{LNC}$ (temperature $22.0^{\circ} \mathrm{C}$ and viscosity $0.95 \mathrm{cP}$ ) and $\operatorname{MTX}(\mathrm{OEt})_{2}-\mathrm{LNC}$ (temperature $20.1^{\circ} \mathrm{C}$ and viscosity $0.99 \mathrm{cP}$ ), respectively, mean sizes of $221 \pm 11 \mathrm{~nm}$ and $197 \pm 13 \mathrm{~nm}$, median diameters (D50) of $212 \pm 20 \mathrm{~nm}$ and $177 \pm 27 \mathrm{~nm}$, and particle number densities of $5.5 \times 10^{12} \pm 0.5 \times 10^{12}$ particles $\mathrm{mL}^{-1}$ and $5.5 \times 10^{12} \pm 0.1 \times 10^{12}$ particles $\mathrm{mL}^{-1}$ (Figure 2).

\section{Induction of apoptosis}

The effect of $\operatorname{MTX}(\mathrm{OEt})_{2}$ solution, $\mathrm{MTX}(\mathrm{OEt})_{2}-\mathrm{LNC}$, and LNC on apoptosis in MCF-7 and MDA-MB-231 human breast adenocarcinoma cells was assessed by flow cytometry with annexin V-PE/7-AAD staining. The results shown in Figure 3 indicate that MTX $(\mathrm{OEt})_{2}$-LNC significantly increased $(P<0.05)$ the apoptotic ratio in both cells compared with control cells. For MCF-7 cells, MTX $(\mathrm{OEt})_{2}$ solution and MTX $(\mathrm{OEt})_{2}$-LNC presented significantly higher $(P<0.05)$ apoptotic rates than both untreated cells and cells incubated with LNC. For MDA-MB-231 cells, MTX $(\mathrm{OEt})_{2}$-LNC were significantly $(P<0.05)$ more efficient in inducing apoptosis than the solution of the free drug. LNC treatment induced apoptosis in MDA-MB-231 cells, but this induction was significantly different than in the MTX $(\mathrm{OEt})_{2}$-LNC treatment group. Concentration of $20 \mu \mathrm{M}$ was more efficient in inducing apoptosis.

\section{Late apoptosis rates}

The rates of late apoptosis induced by $\mathrm{MTX}(\mathrm{OEt})_{2}$ solution, MTX(OEt) ${ }_{2}-\mathrm{LNC}$, and LNC in MCF-7 and MDA-MB-231 human breast adenocarcinoma cells was assessed by flow cytometry with TUNEL (TdT-mediated dUTP nick end labeling) staining. The results are shown in Figure 4. There was no significant difference between groups for MCF-7 cells $(P>0.05)$. Considering treatment group and concentration, $\operatorname{MTX}(\mathrm{OEt})_{2}$-LNC $20 \mu \mathrm{M}$ was different from the treatments at the other concentrations. For MDA-MB-231 cells, $\operatorname{MTX}(\mathrm{OEt})_{2}$-LNC was significantly $(P<0.05)$ more efficient than the solution of the free drug, but LNC treatment also demonstrated induction of apoptosis.

\section{Cell cycle analysis}

The number of cells at the different phases of the cell cycle $\left(\mathrm{G}_{0} / \mathrm{G}_{1}, \mathrm{~S}\right.$, and $\left.\mathrm{G}_{2} / \mathrm{M}\right)$ after treatment with $\operatorname{MTX}(\mathrm{OEt})_{2}$ solution, $\mathrm{MTX}(\mathrm{OEt})_{2}-\mathrm{LNC}$, and LNC, and also of untreated cells, was analyzed by flow cytometry with propidium iodide staining. The results shown in Figure 5 demonstrate that only $\operatorname{MTX}(\mathrm{OEt})_{2}$ solution significantly $(P<0.05)$ altered the cell cycle, causing S-phase arrest. There were no significant differences between groups in $\mathrm{G} 1$ and G2/M phases.

\section{Discussion}

Recently, nanoparticulate drug-delivery systems containing anticancer agents have received much attention. ${ }^{30,31}$ Nanotechnology can be suitable for providing advantages over conventional chemotherapy, since more efficient drug delivery can be achieved with higher intracellular drug concentrations. This approach can serve to minimize the development of MTX resistance by cancer cells, which remains a primary cause of therapy failure in cancer treatment with this drug.

Association of an MTX derivative in a lipid-core nanoformulation may increase cellular uptake and cytotoxicity. Nanocapsules could reduce the multidrug resistance that characterizes many anticancer drugs by a mechanism of cell internalization by endocytosis and by lowering drug efflux from the cells. ${ }^{32}$ When cell internalization of the drug 

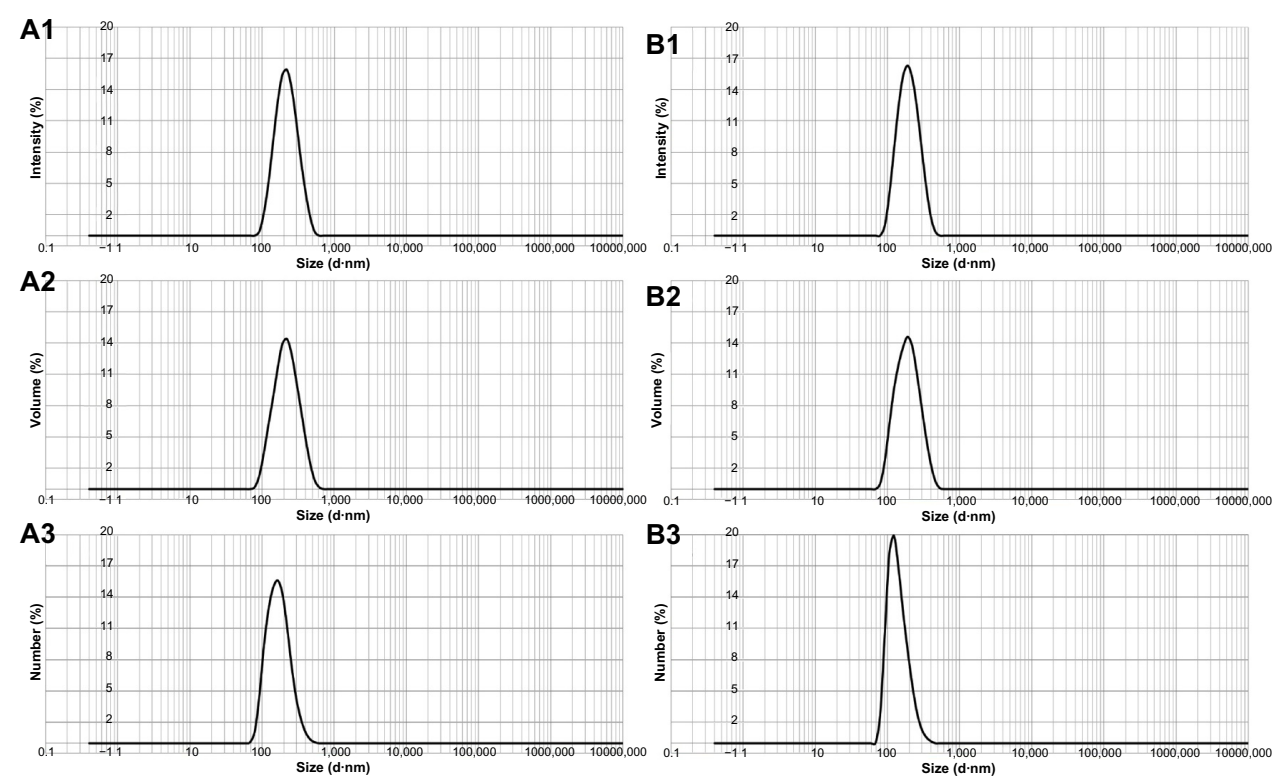

Figure I Granulometric profiles obtained by PCS: (AI) LNC (intensity); (A2) LNC (volume); (A3) LNC (number); (B I) MTX(OEt) ${ }_{2}$-LNC (intensity); (B2) MTX(OEt) ${ }_{2}$-LNC (volume); and (B3) MTX(OEt) ${ }_{2}$-LNC (number).

Abbreviations: LNC, lipid-core nanocapsule; MTX $(\mathrm{OEt})_{2}$, methotrexate diethyl ester; MTX(OEt) ${ }_{2}$-LNC, MTX(OEt) ${ }_{2}$-loaded nanocapsule; PCS, photon correlation spectroscopy.

increases, the pharmacological action of the compound can be optimized. ${ }^{11}$

The formulations prepared, $\mathrm{LNC}$ and $\mathrm{MTX}(\mathrm{OEt})_{2}-\mathrm{LNC}$, presented adequate granulometric profiles. Despite laser diffraction (LD) not being specific in characterizing submicrometric populations, it is a useful technique to exclude the presence of microscopic contamination in the formulations. The sensitivity of this technique is decreased with decreasing particle size..$^{33}$ Both formulations showed narrow size distributions below $1,000 \mathrm{~nm}$. To characterize the nanoscopic populations, PCS and NTA were used. These techniques take into account the Brownian movement of particles dispersed in a liquid medium and use the Stokes-Einstein ${ }^{34}$ equation to give the particle size distributions. PCS gives the mean diameter based on intensity, and NTA gives the mean and median diameters based on the number of particles, having a better resolution of polydispersion because individual particles are analyzed. ${ }^{35} \mathrm{~A}$ large difference between the median diameters obtained by LD or NTA $\left(D_{[n, 0.5]}\right.$ or D50) was observed. $D_{[n, 0.5]}$ calculated from the measurements of LD were lower than $100 \mathrm{~nm}$, while D50 obtained from NTA were close to $200 \mathrm{~nm}$. NTA is a more accurate technique to characterize nanoscopic populations. The similarity between the z-average diameters and the mean diameters obtained by NTA confirmed that the formulations have narrow size distributions, indicating a high homogeneity of particle sizes.

The two breast cancer cell lines used in this study demonstrated that different resistance mechanisms can be exploited for the design of different approaches. The MCF-7 cell line presents MTX resistance by overexpression of DHFR. ${ }^{7}$ In that sense, facilitation of drug transportation into cells by a nanoformulation does not seem to be the approach that
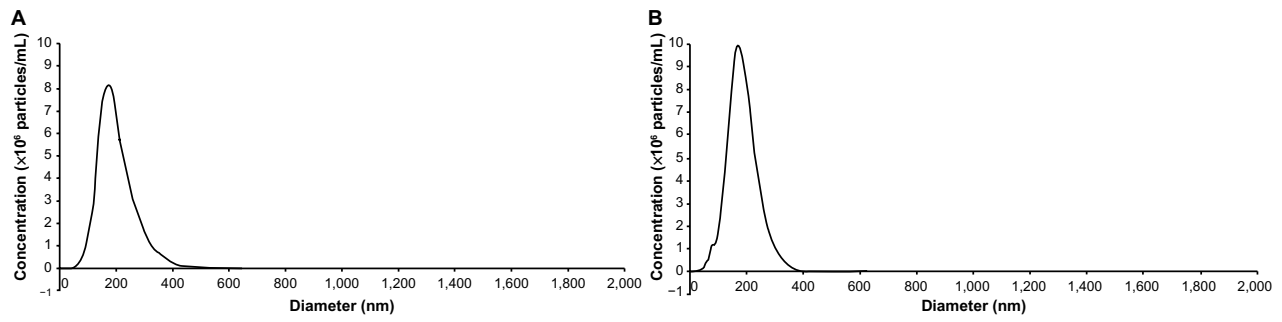

Figure 2 Granulometric profiles obtained by NTA: (A) LNC; (B) MTX(OEt) ${ }_{2}$-LNC. The drug content and the encapsulation efficiency were $0.50 \pm 0.06 \mathrm{mg} \mathrm{mL}^{-1}$ and $99 \% \pm 1 \%$, respectively.

Abbreviations: LNC, lipid-core nanocapsule; MTX(OEt), methotrexate diethyl ester; MTX(OEt) $)_{2}$-LNC, MTX(OEt) $)_{2}$-loaded nanocapsule; NTA, nanoparticle tracking analysis. 


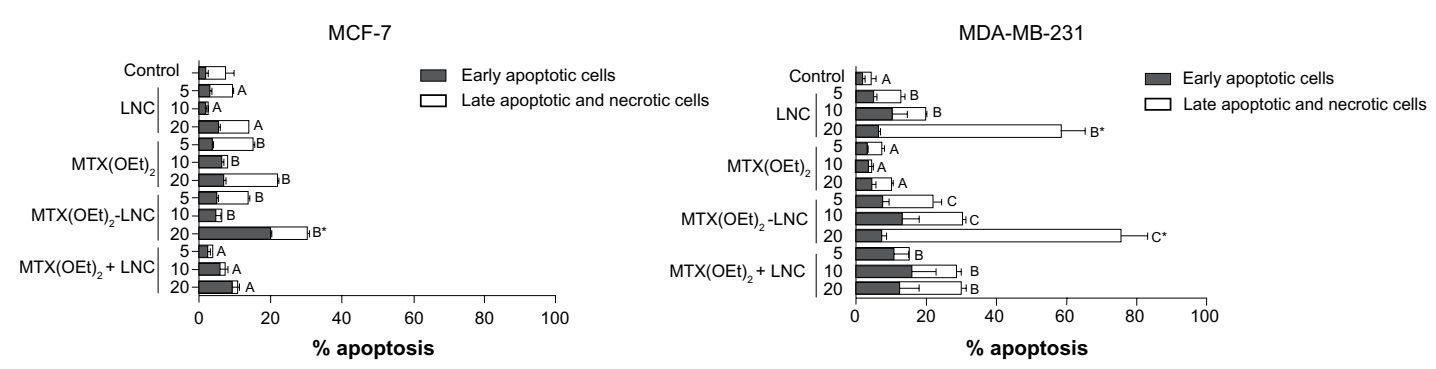

Figure 3 Early apoptosis and late apoptosis or dead cell percentages of MCF-7 and MDA-MB-23I human breast adenocarcinoma cells after 48 hours treatment with MTX(OEt) $)_{2}$ solution, MTX(OEt) $)_{2}$-LNC, and unloaded nanocapsules (LNC).

Notes: Data are expressed as mean \pm standard error of the mean from three independent experiments. A-C indicate significant differences between treatment groups. *Significant differences considering treatment and concentration. Differences were considered significant at $P<0.05$.

Abbreviations: LNC, lipid-core nanocapsule; MTX $(\mathrm{OEt})_{2}$, methotrexate diethyl ester; MTX(OEt) ${ }_{2}$-LNC, MTX $(\mathrm{OEt})_{2}$-loaded nanocapsule.

will overcome the resistance, although pharmacological action can be improved. Accordingly, we did not observe more efficiency of MTX $(\mathrm{OEt})_{2}-\mathrm{LNC}$ compared with the solution of the free drug in MCF-7 cells. On the other hand, highly tumorigenic MDA-MB-231 cell line presents MTX resistance by lack of transport receptors. ${ }^{89}$ For that cell line, MTX(OEt) ${ }_{2}$-LNC treatment was much more effective than MTX $(\mathrm{OEt})_{2}$, demonstrating greater antitumor effects in vitro. Cell internalization of drug-loaded LNCs likely occurs by endocytosis. This was demonstrated for a similar LNC formulation by uptake experiments in the presence of endocytosis inhibitors, with results showing almost complete LNC drug content uptake inhibition by glioma cells. ${ }^{36}$

Also, the present results suggest that the molecular mechanisms associated with apoptosis in the MDA-MB-231 cell line are more sensitive to the nanoformulation evaluated in this study. In this cell line, we observed apoptosis induction by LNCs, without the presence of the drug. Another study showed that unloaded nanoparticles reduce cell viability and they attribute this effect, most likely, to the combined effect of the free amines of the polymer at the nanoparticle surface and the cytotoxic potential of the surfactant by itself. ${ }^{37}$

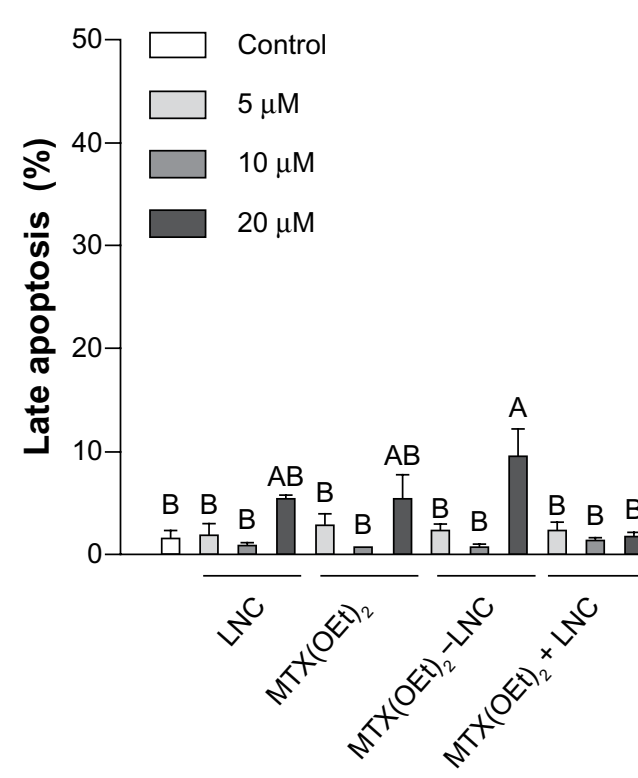

MCF-7

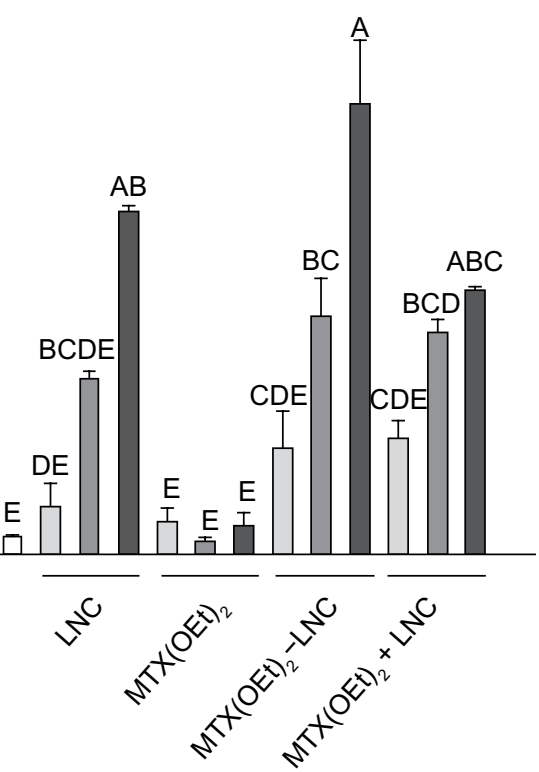

MDA-MB-231

Figure 4 Late apoptosis percentages of MCF-7 and MDA-MB-23I human breast adenocarcinoma cells after 48 hours treatment with MTX(OEt) ${ }_{2}$ solution, MTX(OEt) ${ }_{2}$-LNC, and unloaded nanocapsules (LNC).

Notes: Data are expressed as mean \pm standard error of the mean from three independent experiments. A-E indicate significant differences considering treatment and concentration. Differences were considered significant at $P<0.05$.

Abbreviations: LNC, lipid-core nanocapsule; MTX $(\mathrm{OEt})_{2}$, methotrexate diethyl ester; MTX $(\mathrm{OEt})_{2}$-LNC, MTX(OEt) ${ }_{2}$-loaded nanocapsules. 

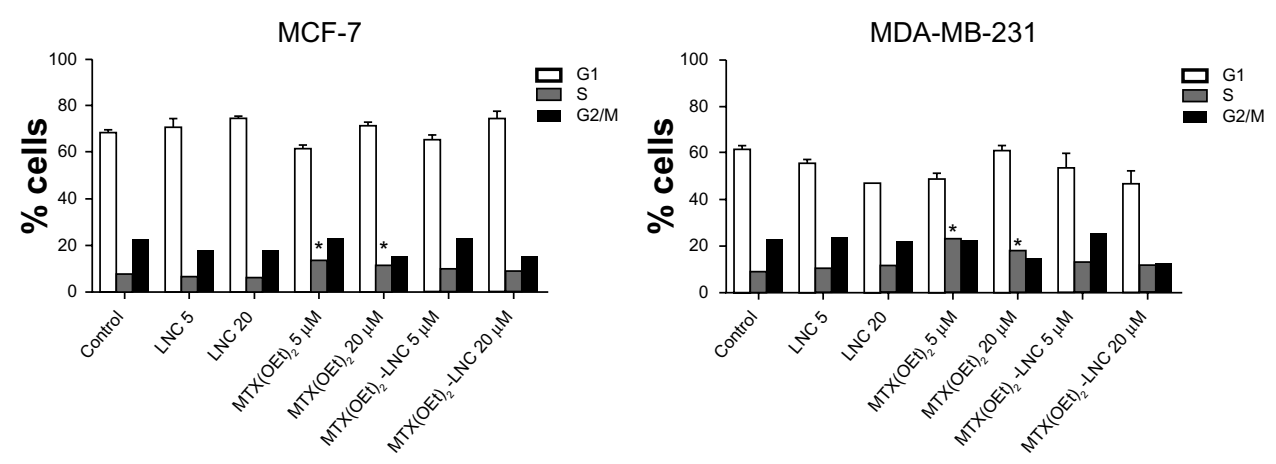

Figure 5 Number of MCF-7 and MDA-MB-23I human breast adenocarcinoma cells in each phase of the cell cycle (GI, S, G2/M) after 48 hours treatment with MTX(OEt) solution, $M T X(\mathrm{OEt})_{2}$-LNC, and unloaded nanocapsules (LNC).

Notes: Data are expressed as mean \pm standard error of the mean from two independent experiments. *Significant differences between treatment groups within the phase. Differences were considered significant at $P<0.05$.

Abbreviations: LNC, lipid-core nanocapsule; MTX $(\mathrm{OEt})_{2}$, methotrexate diethyl ester; MTX(OEt) ${ }_{2}$-LNC, MTX(OEt $)_{2}$-loaded nanocapsule.

When LNCs containing the drug indomethacin were used in in-vitro treatment of glioma cells, the nanoformulation was more effective when compared with the solution of the drug. The LNC formulation reduced cell viability mainly by apoptosis and was also able to induce cell-cycle deregulation. ${ }^{38} \mathrm{In}$ normal cells, the cell cycle is controlled by a complex series of signaling pathways by which a cell grows, replicates its DNA, and divides. ${ }^{39}$ It was demonstrated that an MTX nanoformulation arrested the cell cycle in the S-phase ${ }^{37}$ In contrast, we were not able to detect any significant alteration in cell cycle caused by our MTX(OEt) $)_{2}$-LNC treatment. However, $\mathrm{MTX}(\mathrm{OEt})_{2}$ solution caused cell cycle arrest in S-phase.

It is relevant to search for new effective drug-delivery systems. This study aimed to investigate whether the association of MTX $(\mathrm{OEt})_{2}$ and an LNC formulation could increase antineoplastic effects in resistant cell lines. Relying on the mechanism of resistance, improvement can be achieved. Further study models are required to understand the pharmacokinetic and toxicological profiles of the formulation as well as to investigate its therapeutic efficacy.

\section{Acknowledgments}

This work was supported by the Brazilian funding agencies: Coordenação de Aperfeiçoamento de Pessoal de Nível Superior (CAPES)/Rede Nanobiotec CAPES/PNPD/ CAPES, Conselho Nacional de Desenvolvimento Científico e Tecnológico (CNPq) and Fundação de Amparo à Pesquisa do Rio Grande do Sul (FAPERGS) (PRONEX and PRONEM/ FAPERGS).

\section{Disclosure}

The authors report no conflicts of interest in this work.

\section{References}

1. Jemal A, Siegel R, Ward E, Hao Y, Xu J, Thun MJ. Cancer statistics, 2009. CA Cancer J Clin. 2009;59(4):225-249.

2. Gonen N, Assaraf YG. Antifolates in cancer therapy: structure, activity and mechanisms of drug resistance. Drug Resist Updat. 2012;15(4):183-210.

3. Visentin M, Zhao R, Goldman ID. The antifolates. Hematol Oncol Clin North Am. 2012;26(3):629-648, ix.

4. Zhao R, Goldman ID. Resistance to antifolates. Oncogene. 2003;22(47): 7431-7457.

5. Banerjee D, Mayer-Kuckuk P, Capiaux G, Budak-Alpdogan T, Gorlick R, Bertino JR. Novel aspects of resistance to drugs targeted to dihydrofolate reductase and thymidylate synthase. Biochim Biophys Acta. 2002;1587(2-3):164-173

6. Yoon SA, Choi JR, Kim JO, Shin JY, Zhang X, Kang JH. Influence of reduced folate carrier and dihydrofolate reductase genes on methotrexateinduced cytotoxicity. Cancer Res Treat. 2010;42(3):163-171.

7. Selga E, Oleaga C, Ramirez S, de Almagro MC, Noe V, Ciudad CJ. Networking of differentially expressed genes in human cancer cells resistant to methotrexate. Genome Med. 2009;1(9):83.

8. Moscow JA, Connolly T, Myers TG, Cheng CC, Paull K, Cowan KH. Reduced folate carrier gene (RFC1) expression and anti-folate resistance in transfected and non-selected cell lines. Int J Cancer. 1997;72(1): 184-190.

9. Yang R, Li WW, Hoang BH, et al. Quantitative correlation between promoter methylation and messenger RNA levels of the reduced folate carrier. BMC Cancer. 2008;8:124.

10. Santos MA, Enyedy EA, Nuti E, Rossello A, Krupenko NI, Krupenko SA. Methotrexate gamma-hydroxamate derivatives as potential dual target antitumor drugs. Bioorg Med Chem. 2007;15(3):1266-1274.

11. Moura JA, Valduga CJ, Tavares ER, Kretzer IF, Maria DA, Maranhao RC. Novel formulation of a methotrexate derivative with a lipid nanoemulsion. Int J Nanomedicine. 2011;6:2285-2295.

12. Peer D, Karp JM, Hong S, Farokhzad OC, Margalit R, Langer R. Nanocarriers as an emerging platform for cancer therapy. Nat Nanotechnol. 2007;2(12):751-760.

13. Torchilin VP. Drug targeting. Eur J Pharm Sci. 2000;11 Suppl 2: S81-S91.

14. Vauthier C, Bouchemal K. Methods for the preparation and manufacture of polymeric nanoparticles. Pharm Res. 2009;26(5):1025-1058.

15. Mora-Huertas CE, Fessi H, Elaissari A. Polymer-based nanocapsules for drug delivery. Int J Pharm. 2010;385(1-2):113-142.

16. Jager E, Venturini CG, Poletto FS, et al. Sustained release from lipidcore nanocapsules by varying the core viscosity and the particle surface area. J Biomed Nanotechnol. 2009;5(1):130-140. 
17. Muller CR, Schaffazick SR, Pohlmann AR, et al. Spray-dried diclofenacloaded poly(epsilon-caprolactone) nanocapsules and nanospheres. Preparation and physicochemical characterization. Pharmazie. 2001;56(11):864-867.

18. Cruz L, Schaffazick SR, Dalla CT, et al. Physico-chemical characterization and in vivo evaluation of indomethacin ethyl ester-loaded nanocapsules by PCS, TEM, SAXS, interfacial alkaline hydrolysis and antiedematogenic activity. J Nanosci Nanotechnol. 2006;6(9-10): 3154-3162.

19. Fiel L, Rebelo L, Santiago T, et al. Diverse deformation properties of polymeric nanocapsules and lipid-core nanocapsules. Soft Matter. 2011;7:7240-7247.

20. Venturini C, Jäger E, Oliveira C, et al. Formulation of lipid core nanocapsules. Colloids Surf A Physicochem Eng Asp. 2011;375: 200-208.

21. Jornada DS, Fiel L, Bueno K, et al. Lipid-core nanocapsules: mechanism of self-assembly, control of size and loading capacity. Soft Matter. 2012;8:6646-6655.

22. Figueiro F, Bernardi A, Frozza RL, et al. Resveratrol-loaded lipid-core nanocapsules treatment reduces in vitro and in vivo glioma growth. J Biomed Nanotechnol. 2013;9(3):516-526.

23. Bernardi A, Frozza RL, Horn AP, et al. Protective effects of indomethacinloaded nanocapsules against oxygen-glucose deprivation in organotypic hippocampal slice cultures: involvement of neuroinflammation. Neurochem Int. 2010;57(6):629-636.

24. Bernardi A, Zilberstein AC, Jager E, et al. Effects of indomethacinloaded nanocapsules in experimental models of inflammation in rats. Br J Pharmacol. 2009;158(4):1104-1111.

25. Bernardi A, Braganhol E, Jager E, et al. Indomethacin-loaded nanocapsules treatment reduces in vivo glioblastoma growth in a rat glioma model. Cancer Lett. 2009;281(1):53-63.

26. Pohlmann AR, Fonseca FN, Paese K, et al. Poly(-caprolactone) microcapsules and nanocapsules in drug delivery. Expert Opin Drug Deliv. 2013;10(5):623-638.

27. Bulcao RP, Freitas FA, Venturini CG, et al. Acute and subchronic toxicity evaluation of poly(epsilon-caprolactone) lipid-core nanocapsules in rats. Toxicol Sci. 2013;132(1):162-176.
28. Oliveira C, Venturini C, Donida B, Poletto F, Guterres SS, Pohlmann AR. An algorithm to determine the mechanism of drug distribution in lipidcore nanocapsule formulations. Soft Matter. 2013;9:1141-1150.

29. Allen RT, Hunter WJ III, Agrawal DK. Morphological and biochemical characterization and analysis of apoptosis. J Pharmacol Toxicol Methods. 1997;37(4):215-228.

30. Bawarski WE, Chidlowsky E, Bharali DJ, Mousa SA. Emerging nanopharmaceuticals. Nanomedicine. 2008;4(4):273-282.

31. Misra R, Acharya S, Sahoo SK. Cancer nanotechnology: application of nanotechnology in cancer therapy. Drug Discov Today. 2010;15(19-20):842-850.

32. Mei L, Zhang Y, Zheng Y, et al. A novel docetaxel-loaded poly (epsilon-caprolactone)/pluronic F68 nanoparticle overcoming multidrug resistance for breast cancer treatment. Nanoscale Res Lett. 2009;4(12): 1530-1539.

33. Stojanović Z, Marković S, Uskoković D. Determination of particle size distributions by laser diffraction. Technics New Mater. 2012;21: 11-20.

34. Berne BJ, Pecora R. Dynamic light scattering: with applications to chemistry, biology and physics. New York: Wiley, c 1976.

35. Filipe V, Hawe A, Jiskoot W. Critical evaluation of nanoparticle tracking analysis (NTA) by NanoSight for the measurement of nanoparticles and protein aggregates. Pharm Res. 2010;27(5):796-810.

36. Zanotto-Filho A, Coradini K, Braganhol E, et al. Curcumin-loaded lipid-core nanocapsules as a strategy to improve pharmacological efficacy of curcumin in glioma treatment. Eur J Pharm Biopharm. 2013;83:156-167.

37. Nogueira DR, Tavano L, Mitjans M, Perez L, Infante MR, Vinardell MP. In vitro antitumor activity of methotrexate via $\mathrm{pH}$-sensitive chitosan nanoparticles. Biomaterials. 2013;34(11):2758-2772.

38. Bernardi A, Frozza RL, Hoppe JB, et al. The antiproliferative effect of indomethacin-loaded lipid-core nanocapsules in glioma cells is mediated by cell cycle regulation, differentiation, and the inhibition of survival pathways. Int J Nanomedicine. 2013;8:711-728.

39. Rastogi N, Mishra DP. Therapeutic targeting of cancer cell cycle using proteasome inhibitors. Cell Div. 2012;7(1):26.
International Journal of Nanomedicine

\section{Publish your work in this journal}

The International Journal of Nanomedicine is an international, peerreviewed journal focusing on the application of nanotechnology in diagnostics, therapeutics, and drug delivery systems throughout the biomedical field. This journal is indexed on PubMed Central,

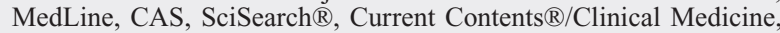

\section{Dovepress}

Journal Citation Reports/Science Edition, EMBase, Scopus and the Elsevier Bibliographic databases. The manuscript management system is completely online and includes a very quick and fair peer-review system, which is all easy to use. Visit http://www.dovepress.com/ testimonials.php to read real quotes from published authors. 